\title{
RELATION OF THE RATE OF HYOID MOVEMENT TO BODY WEIGHT AND TEMPERATURE IN DIVING SOFT-SHELL TURTLES*
}

\author{
WILLIAM A. DUNSON† \\ Department of Zoology, The University of Michigan, Ann Arbor, Michigan, U.S.A.
}

(Received 27 May 1966)

\begin{abstract}
Standard hyoid rate (movements/g min) of soft-shell turtles (Trionyx spinifer) was inversely related to body weight.

2. The $Q_{10}$ of standard hyoid rate was also inversely proportional to body weight.
\end{abstract}

\section{INTRODUCTION}

SoFT-SHELL turtles (Trionyx spinifer spinifer) are anatomically specialized for burrowing in soft bottoms of fresh-water streams and lakes. They are also well adapted physiologically for an aquatic existence, being able to respire under water primarily through villi found on the pharynx (Dunson, 1960). The pharynx of these turtles has also been implicated in the active uptake of sodium from water (Dunson, 1965). Pumping movements of the hyoid apparatus, which draw water into the mouth, are instrumental in supplying oxygen and sodium to the pharynx. These movements also introduce water into the nasal cavities for olfaction. The purpose of this study was to investigate the relation of hyoid movement rate to body weight and temperature.

\section{MATERIAL AND METHODS}

Ten soft-shell turtles ( $T$. s. spinifer) were used, including five immatures, three adult males and two adult females. These animals were weighed on a triple-beam balance of appropriate sensitivity and ranged from 12.6 to $1950.5 \mathrm{~g}$. In the first experiment, hyoid movements of seven turtles in voluntary dives at $22.5^{\circ} \mathrm{C}$ were counted over a period and timed with a stopwatch. In the second experiment three turtles were placed in aquaria in a Hotpack temperaturecontrolled room for a minimum of $8 \mathrm{hr}$ at any one temperature. Their cloacal temperatures, taken with a Schultheiss thermometer, were the same as the water temperatures. Hyoid movements were counted as before. The frequency of these movements varied markedly with the state of activity and probably also with the N.I.H.

* Supported in part by grants 5T1-GM-989-03 and 1-F1-GM-18, 741-01A1 from the

$\dagger$ Present address: Department of Zoology, The Pennsylvania State University, University Park, Pennsylvania. 
duration of the dive. Therefore readings were taken only when the turtle was resting quietly on the bottom or buried in sand. Measurements were made at frequent intervals during the dive and averaged. At lower temperatures, dives were of greater duration and hyoid movements sometimes became infrequent, particularly when activity was low. Below $8^{\circ} \mathrm{C}$ the movements were too sporadic to count. In this range skin respiration and internal oxygen stores presumably provided a larger percentage of the needed oxygen than at higher temperatures. It is not known whether or not these turtles utilize anaerobic respiration while diving.

\section{RESULTS}

Due to the regular nature of hyoid movements in soft-shells, it was possible to quantify their weight and temperature dependence. Log hyoid movements/ ( $\mathrm{g}$ min) bears an inverse linear relation to the log of body weight (Fig. 1). Body weights of these seven soft-shells varied from $12 \cdot 6$ to $1950 \cdot 5 \mathrm{~g}$, a factor of 155 .

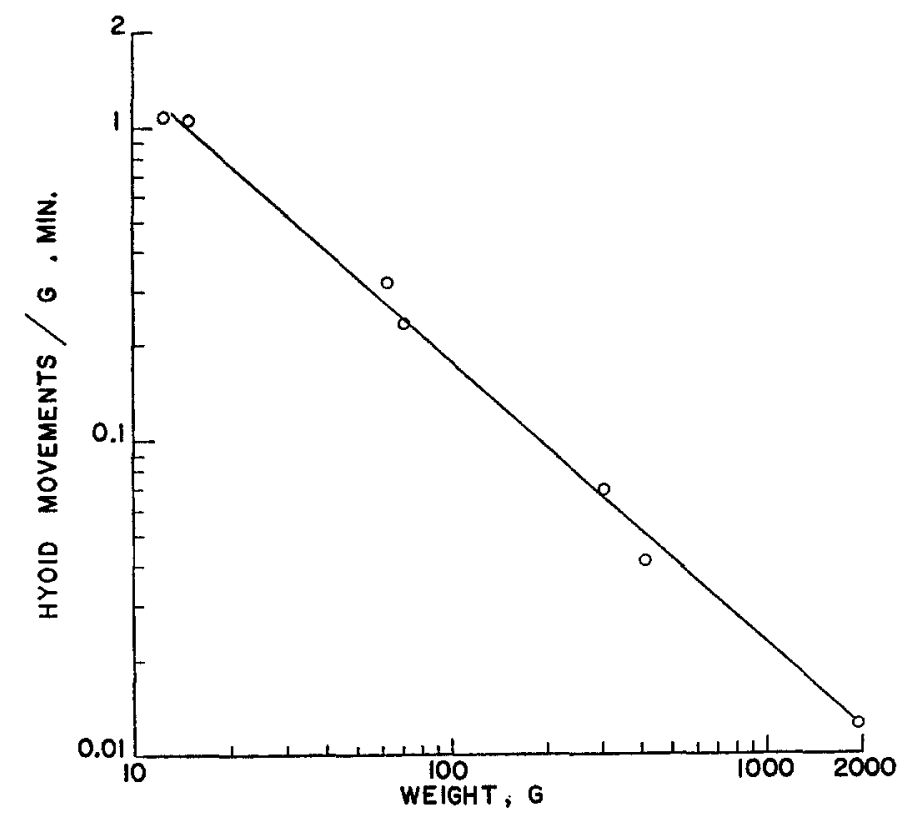

FIG. 1. Relation of standard hyoid rate (movements/g $\mathrm{min}$ ) to body weight in diving $T$. s. spinifer at $22 \cdot 5^{\circ} \mathrm{C}$.

Hyoid frequency (movements/min) varied from 13.6 to $24 \cdot 1$, respectively. This relationship (Fig. 1) is similar to that found between standard metabolic rate as measured by aquatic respiration and body weight in diving $T$. s. asper (Dunson, 1960). In both cases there is an inverse exponential relation between the measured parameter and body weight. Since hyoid movements are supplying oxygen to a respiratory membrane, the pharynx, the similarities are not surprising. 
The thermal dependence of hyoid frequency is of interest since metabolism in turtles is inhibited by cold. The standard hyoid rate (movements/g min) was directly related to body temperature. On a double logarithmic plot (Fig. 2) an essentially linear relation exists between these parameters. The response to temperature appears to vary with body weight (Fig. 2). The smaller the turtle,
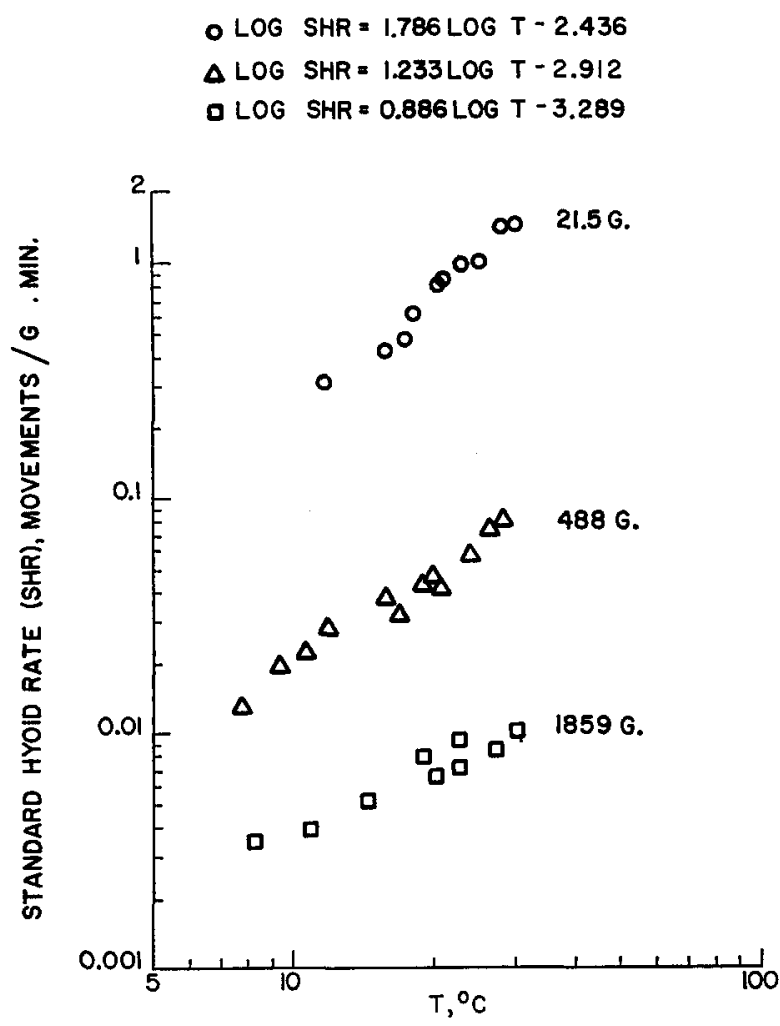

FIG. 2. The temperature dependence of standard hyoid rate in three $T$. s. spinifer.

the greater was the effect of temperature $\left(Q_{10}\right)$ on standard hyoid movement rate. A Student's $t$-test was run between the regression coefficients of each of the functions fitted with a straight line by the least-squares method. Each of the slopes differs significantly from the others $(P<0.01)$. The effects of both weight and temperature on standard hyoid movement rate are shown in Fig. 3. Clearly, a smaller turtle has a larger standard hyoid rate (SHR) at any temperature, and the rate of change of the SHR with temperature is greater than in a larger turtle.

\section{DISCUSSION}

The effect of body weight on standard hyoid rate can be attributed to the respiratory nature of the hyoid movements. Temperature dependence in general 
may be due to effects on metabolic rate. However, the modulation of the temperature-SHR relation by weight is puzzling. It may indicate that the $Q_{10}$ for metabolic rate/g is also size-dependent.

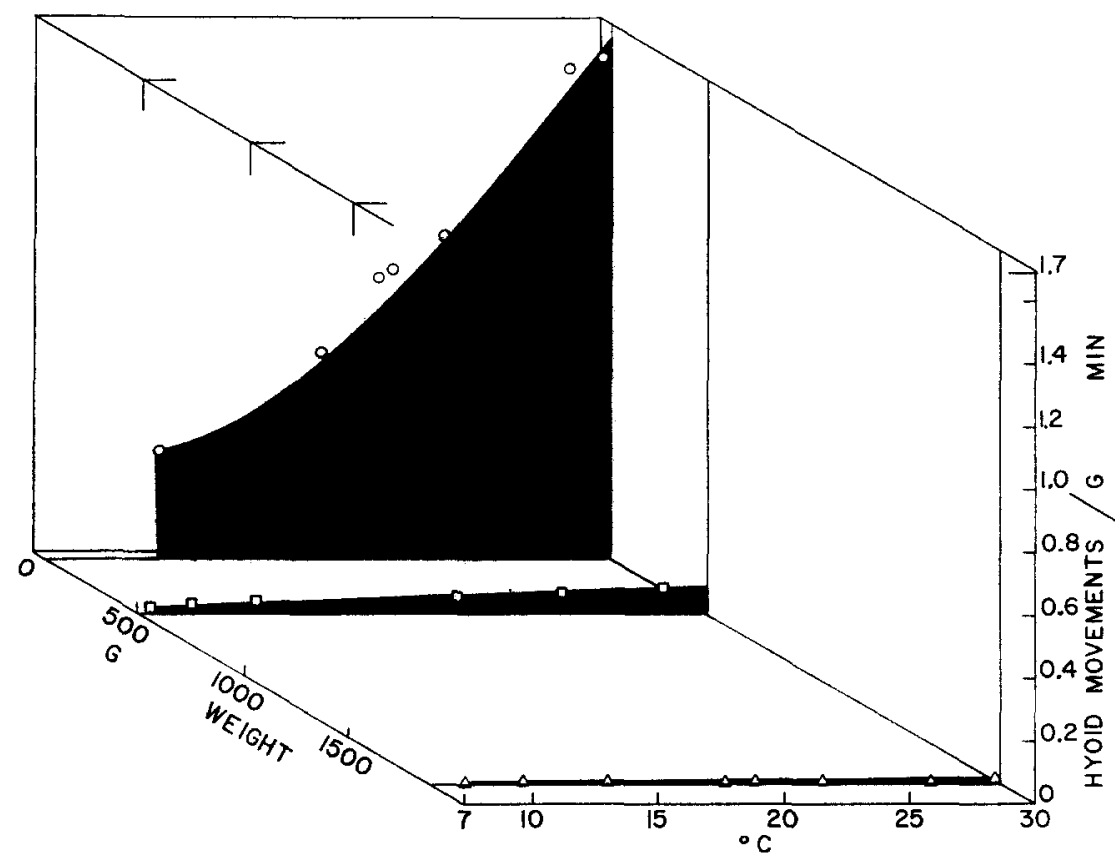

Fig. 3. The relation of standard hyoid rate in T. s. spinifer to temperature and body weight.

Hutton et al. (1960) reported that size has no effect on aerial oxygen consumption $\left(\mathrm{cm}^{3} / \mathrm{g} \mathrm{hr}\right)$ at different temperatures in Pseudemys scripta weighing between 233 and $1805 \mathrm{~g}$ (eightfold range). Baldwin (1926) and Benedict (1932) reported similar findings on other species of turtles with size ranges of sevenfold and twenty-sixfold respectively. Benedict (1932) had only a twofold range for a single species. These results are difficult to explain since in lizards (Cook, 1949; Dawson \& Bartholomew, 1956; Bartholomew \& Tucker, 1964) and snakes (Galvão et al., 1965) larger animals have a proportionately smaller oxygen consumption/weight. If turtles were exceptional in this respect, it would be surprising. When respiring under water, soft-shell turtles over a hundredfold size range demonstrated an inverse correlation between weight and metabolic rate/g (Dunson, 1960). It is possible that Hutton et al. (1960), Baldwin (1926) and Benedict (1932) failed to find this relationship for aerial respiration because the size range of their turtles was too small. The problem will remain unresolved until metabolic measurements are completed on a series of turtles of a single species differing in weight fifty-to a hundredfold. It is important that this be done with a single species because of interspecific physiological variations. 
Rao \& Bullock (1954) reported that, in general, the $Q_{10}$ of various measures of activity in poikilotherms increases with size. Apparently there have been no previous reports in reptiles of metabolically related processes, such as hyoid movements (movements/g min), whose $Q_{10}$ is inversely proportional to body weight. It will be most interesting if these results indicate that the $Q_{10}$ of metabolic rate/g itself is weight-dependent.

\section{REFERENCES}

BALDwiN F. M. (1926) Notes on oxygen consumption in turtles, Chrysemys marginata and Chelydra serpentina Linne. Proc. Iowa Acad. Sci. 33, 315-323.

BARTHOlOMEW G. A. \& TUCKER V. A. (1964) Size, body temperature, thermal conductance, oxygen consumption, and heart rate in Australian varanid lizards. Physiol. Zool. 37, 341-354.

Benedict F. G. (1932) The physiology of large reptiles. Publs Carnegie Instn No. 425, pp. $337-407,431-432$.

Cook S. F. (1949) Respiratory metabolism of certain reptiles and amphibia. Univ. Calif. Publs Zool. 53, 367-376.

Dawson W. R. \& Bartholomew G. A. (1956) Relation of oxygen consumption to body weight, temperature, and temperature acclimation in lizards Uta stansburiana and Sceloporus occidentalis. Physiol. Zool. 29, 40-51.

Dunson W. A. (1960) Aquatic respiration in Trionyx spinifer asper. Herpetologica 16, 277-283.

Dunson W. A. (1965) Active uptake of sodium by softshell turtles (Trionyx spinifer). Science, N.Y. 149, 67-69.

Galvão P. E., Tarasantchi J. \& Guertzenstein P. (1965) Heat production of tropical snakes in relation to body weight and body surface. Am. F. Physiol. 209, 501-506.

Hutton K. E., Boyer D. R., Williams J. C. \& Campbell P. M. (1960) Effects of temperature and body size upon heart rate and oxygen consumption in turtles. F. cell comp. Physiol. 55, 87-93.

RAo K. P. \& Bullock T. H. (1954) $Q_{10}$ as a function of size and habitat temperature in poikilotherms. Am. Nat. 88, 33-44. 